\title{
Introduction to the Special Section on Integrative Approaches to Source Memory
}

\author{
Marcia K. Johnson \\ Yale University
}

\author{
Mieke Verfaellie \\ Boston Veterans Affairs Healthcare System and Boston \\ University School of Medicine
}

\author{
John Dunlosky \\ Kent State University
}

\begin{abstract}
Source memory involves recognizing or recalling particular features that cause us to think of a mental experience as representing a particular past event. Research directed at understanding source memory comes from many domains, including cognitive-behavioral psychology, neuroscience, lifespan psychology, clinical psychology, and psychiatry. The authors believe that integrating multiple approaches to investigating source memory-most notably here, cognitive-behavioral and cognitive neuroscienceprovides productive cross-fertilization of theory, methods, and analyses that in turn will yield unique constraints to our understanding of human memory. The investigations in this special section demonstrate the promise of such an integrative approach for advancing theories of source memory.
\end{abstract}

Our experiences consist of many facets: where and when they happened, the perceptual properties of the people and objects involved, what was said, the emotional state of participants, our interpretations of what happened, and so forth. It is the particular combinations of these facets that differentiate one event from another. The study of source memory is concerned with how such facets become bound together during encoding and how they are later revived and evaluated during remembering (e.g., Johnson, 2006). Source memory can be studied by investigating memory for particular features of events such as location or color of objects, speaker, modality, or emotional tone. It can also be studied by investigating how such features influence attributions about the types of events that are being remembered (e.g., high levels of perceptual, spatial, temporal, and/or emotional detail typically are taken as evidence that an event actually happened rather than was only imagined) or how knowledge and beliefs (expertise, stereotypes, associations) or goals (e.g., to be accurate or fast) influence what is encoded, retrieved, and/or evaluated during remembering. Thus, the study of source memory encompasses, and is broader than, what is usually addressed in the study of context memory.

Researchers have long used cognitive-behavioral approaches to investigate the conditions affecting the attribution of mental experiences to specific episodic or autobiographical events. Recent developments in neuroscience provide an exciting new avenue to explore this fundamental cognitive function. Understanding the cognitive psychology of source memory involves clarifying the

Marcia K. Johnson, Department of Psychology, Yale University; Mieke Verfaellie, Memory Disorders Research Center-Boston Veterans Affairs Healthcare System and Boston University School of Medicine; John Dunlosky, Department of Psychology, Kent State University.

Correspondence concerning this article should be addressed to Marcia K. Johnson, Department of Psychology, Yale University, P.O. Box 208205, New Haven, CT 06520-8205. E-mail: marcia.johnson@yale.edu processes that operate during encoding, revival, and evaluation of memories; the information those processes operate on; and the circumstances influencing these processes. Understanding the neuroscience of source memory involves clarifying the relation between cognitive concepts of "processes" and "information" and neural structures and events (i.e., neural mechanisms).

The studies included in the special section on source memory illustrate the productive cross-fertilization that has developed between cognitive-behavioral approaches and neuroscience approaches over the last few years. Each study illustrates a somewhat different integration of these two general approaches and a focus on different aspects of source memory. The studies highlight cognitive-behavioral methods (Diana, Yonelinas, \& Ranganath, 2008; Elfman, Parks, \& Yonelinas, 2008); neuroimaging methods, including functional magnetic resonance imaging (Awipi \& Davachi, 2008; Dennis et al., 2008; Mitchell et al., 2008) and eventrelated potentials (Leynes \& Phillips, 2008); neuropsychological methods comparing young and older adult populations (Dennis et al., 2008; Glisky \& Kong, 2008); and neurocomputational modeling of source memory (Elfman et al., 2008).

The studies highlight how cognitive theory-in particular, dual process theory (e.g., Yonelinas, 1994, 2002) and the sourcemonitoring framework (SMF; Johnson, 2006; Johnson, Hashtroudi, \& Lindsay, 1993) — can contribute to interpreting the psychological function of neural activity. At the same time, the challenge of finding compelling psychological explanations of neural activity that are consistent across studies using different procedures provides a new source of constraints on cognitive theories. Furthermore, neuroscience findings pose puzzles that can guide behavioral studies that will further elucidate the cognitive mechanisms underlying source memory. Looking for coherence between different levels of analysis or types of evidence is a challenging endeavor, but the potential payoff is converging evidence for each. 
The articles in this special section illustrate a conversation in progress, not a final report. The voices represented by different methods add to the richness of the conversation, and themes are emerging. One theme is that results emanating from dual process approaches that emphasize the difference between recollection and familiarity (Diana et al., 2008) and those from the SMF approach that focus on varying qualities of recollection (Leynes \& Phillips, 2008; Mitchell et al., 2008) are not necessarily contradictory (Elfman et al., 2008). Combining simulations on the basis of a computational neuroscience model (Norman \& O'Reilly, 2003) and cognitive-behavioral findings, Elfman et al. (2008) demonstrate that a threshold model (as assumed by dual process theory) may fit source memory under some circumstances, but a graded model (as assumed by the SMF) appears better under others.

Neuroimaging evidence points to the need to further clarify concepts such as familiarity, recollection, and source. For example, Leynes and Phillips (2008) conducted an event-related potential (ERP) study showing evidence (the parietal old-new effect) that, under some circumstances, "know" responses (often taken as evidence of familiarity without recollection) may reflect some degree of graded recollection. Diana et al.'s (2008) research was motivated by an inconsistency in neuroimaging findings. Neuroimaging studies have typically shown hippocampal activity associated with accurate source memory and perirhinal activity associated with item memory. This pattern is often interpreted as reflecting the difference between recollection and familiarity, respectively. However, Staresina and Davachi (2006) reported activity in the perirhinal cortex during encoding associated with later accurate source memory. Diana et al. (2008) used cognitivebehavioral methods (analysis of source ROCs) to demonstrate that familiarity can contribute to source memory when a to-beremembered item and its source are unitized. Thus, they suggest that familiarity associated with unitized information may account for perirhinal activity associated with source memory. The generality of this solution may be challenged by the findings of Awipi and Davachi (2008), whose study focuses on perirhinal activation during encoding. They also make the point that important differences may exist in types of source information and emphasize that neuroimaging studies have not explored the full range of types of feature, for example, as outlined in the SMF. They argue that there is much neural evidence that the perirhinal cortex is involved in perceptual processing of objects, suggesting that perirhinal cortex also may be involved in a more specific type of feature memory than simply familiarity (or as well as familiarity). They then show encoding activity in perirhinal cortex associated with later source memory when the source is an object paired with a scene. Thus, together the Diana et al. and the Awipi and Davachi articles highlight the importance of exploring a wide range of types of source information and the need to clarify the conceptual relation between memory for specific details and familiarity. Identifying neural mechanisms (e.g., perirhinal vs. hippocampal) associated with types of information (unitized vs. nonunitized; simple vs. complex; similar vs. dissimilar) should help us to further refine our theoretical concepts.

Another important theme is that source memory is the result of agenda-driven processes that are selective. For example, neural activity depends on the features that are attended to at encoding (Awipi \& Davachi, 2008) and the features that are monitored at test (Mitchell et al., 2008). In particular, Mitchell et al. (2008) found differences in prefrontal activity during source monitoring related to selectively attending to different features (format vs. task performed). They also report neural evidence that competition between active features may be asymmetrical during source monitoring and suggest that much neural activity seen in long-term source memory studies may reflect evaluation of active information.

Another ongoing theme in source memory research is that changes associated with normal aging provide a valuable perspective on source memory processes and mechanisms. Dennis et al. (2008), testing binding-deficit theories of aging arising from the cognitive literature, show that the hippocampal and frontal activations at encoding that predict successful long-term source memory in young adults are reduced in older adults. Glisky and Kong (2008) also demonstrate that binding processes - such as those involved in integrating features-place greater working-memory demands on older adults than on young adults. Such findings emphasize the need to further specify, in healthy young adults, how medial temporal, frontal, parietal, and other areas work together during feature binding and during the revival and evaluation of information (Dennis et al., 2008).

We are only just beginning to understand how different brain regions work together to engage in the processes that create, and later revive and monitor, event representations. Already we know that there is not a single source memory process or a single source memory brain region responsible for the subjective experience of remembering specific events. Requiring that the theoretical concepts we propose to organize our understanding satisfy constraints from multiple types of evidence provides a stringent means of testing them.

\section{References}

Awipi, T., \& Davachi, L. (2008). Content-specific source encoding in human medial temporal lobe. Journal of Experimental Psychology: Learning, Memory, and Cognition, 34, 769-779.

Dennis, N. A., Hayes, S. M., Prince, S. E., Madden, D. J., Huettel, S. A., \& Cabeza, R. (2008). Effects of aging on the neural correlates of successful item and source memory encoding. Journal of Experimental Psychology: Learning, Memory, and Cognition, 34, 791-808.

Diana, R. A., Yonelinas, A. P., \& Ranganath, C. (2008). The effects of unitization on familiarity-based source memory: Testing a behavioral prediction from neuroimaging data. Journal of Experimental Psychology: Learning, Memory, and Cognition, 34, 730-740.

Elfman, K. W., Parks, C. M., \& Yonelinas, A. P. (2008). Testing a neurocomputational model of recollection, familiarity, and source recognition. Journal of Experimental Psychology: Learning, Memory, and Cognition, 34, 752-768.

Glisky, E. L., \& Kong, L. L. (2008). Do young and older adults rely on different processes in source memory tasks? A neuropsychological study. Journal of Experimental Psychology: Learning, Memory, and Cognition, 34, 809-822.

Johnson, M. K. (2006). Memory and reality. American Psychologist, 61, $760-771$.

Johnson, M. K., Hashtroudi, S., Lindsay, D. S. (1993). Source monitoring. Psychological Bulletin, 114, 3-28.

Leynes, P. A., \& Phillips, M. C. (2008). Event-related potential (ERP) evidence for varied recollection during source monitoring. Journal of Experimental Psychology: Learning, Memory, and Cognition, 34, 741751.

Mitchell, K. J., Raye, C. R., McGuire, J. T., Frankel, H., Greene, E. J., \& 
Johnson, M. K. (2008). Neuroimaging evidence for agenda-dependent monitoring of different features. Journal of Experimental Psychology: Learning, Memory, and Cognition, 34, 780-790.

Norman, K. A., \& O'Reilly, R. C. (2003). Modeling hippocampal and neocortical contributions to recognition memory: A complementarylearning-systems approach. Psychological Review, 110, 611-646.

Staresina, B. P., \& Davachi, L. (2006). Differential encoding mechanisms for subsequent associative recognition and free recall. Journal of Neuroscience, 26, 9162-9172.

Yonelinas, A. P. (1994). Receiver operating characteristics in recognition memory: Evidence for a dual process model. Journal of Experimental Psychology: Learning, Memory, and Cognition, 20, 1341-1354.

Yonelinas, A. P. (2002). The nature of recollection and familiarity: A review of 30 years of research. Journal of Memory and Language, 46, $441-517$.

Received April 21, 2008 Revision received April 23, 2008

Accepted April 23, 2008

\section{ORDER FORM}

Start my 2008 subscription to Journal of Experimental Psychology: Learning, Memory, and Cognition ISSN: 0278-7393

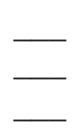

\$152.00, APA Member/Affiliate \$332.00, INDIVIDUAL NoNMEMBER $\$ 900.00$, Institution In DC add $5.75 \%$ / In MD add 6\% sales tax Total Amount Enclosed

$\$$

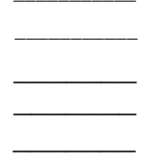

Subscription orders must be prepaid. (Subscriptions are on a calendar year basis only.) Allow 4-6 weeks for delivery of the first issue. Call for international subscription rates.

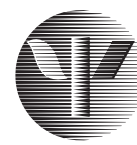

AMERICAN PSYCHOLOGICAL ASSOCIATION

\section{SEND THIS ORDER FORM TO:}

American Psychological Association Subscriptions

750 First Street, NE

Washington, DC 20002-4242

Or call 800-374-2721, fax 202-336-5568.

TDD/TTY 202-336-6123.

For subscription information, e-mail: subscriptions@apa.org
Check enclosed (make payable to APA)

Charge my: $\bigcirc$ VISA $\bigcirc$ MasterCard $\bigcirc$ American Express

Cardholder Name

Card No. Exp. Date

Signature (Required for Charge)

BILLING ADDRESS:

Street

City_ State __ Zip

Daytime Phone

E-mail

MAIL TO:

Name

Address

City _ State _ Z Zip

APA Member \# XLMA08 